\title{
O valido em cena. Política, história e crítica social em ¿Cómo ha de ser el privado?, de Francisco de Quevedo
}

\author{
The valido in scene. Politics, history and \\ social criticism in ¿Cómo ha de ser el privado?, \\ of Francisco de Quevedo \\ El valido en escena. Política, historia y \\ crítica social en ¿Cómo ha de ser el privado?, \\ de Francisco de Quevedo
}

\author{
Ricardo de Oliveira ${ }^{a}$ \\ Karenina do Nascimento Rodrigues ${ }^{\mathrm{b}}$
}

\begin{abstract}
Resumo: O valido foi uma personagem polêmica durante o século XVII no âmbito da cultura política do Antigo Regime. Este artigo pretende oferecer uma análise de como o valido foi tratado dentro do gênero de dramaturgia denominado Comedia de la Privanza, atendo-se à comédia ¿Cómo ha de ser el privado?, de Francisco de Quevedo, que coloca questões relevantes acerca do fenômeno do valimento, bem como da controversa relação de Quevedo com o regime do conde-duque de Olivares, valido de Felipe IV.
\end{abstract}

Palavras-chave: Espanha no século XVII. ¿Cómo ha de ser el privado? Valido.

Abstract: The valido was a polemic personage during the $17^{\text {th }}$ century in the ambit of the political culture on the Ancien Regime. This article aims to provide an analysis of how valido was treated within the genre of dramaturgy called Comedia de la Privanza, in keeping with Francisco de Quevedo’s comedy ¿Cómo ha de ser el privado?, which poses relevant questions about the phenomenon of valimento, as well as Quevedo's controversial relationship with the Count-Duke of Olivares' regime, valido of Felipe IV.

Keywords: Spain in the $17^{\text {th }}$ century. ¿Cómo ha de ser el privado? Valido.

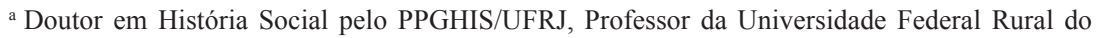
Rio de Janeiro

${ }^{\text {b }}$ Mestranda do Programa de Pós-Graduação em História da Universidade Federal Rural do Rio de Janeiro (PPHR).
} 
Resumen: El valido fue un polémico personaje en el siglo XVII en el ámbito de la cultura política del Antiguo Régimen. Este texto busca ofrecer un análisis acerca de cómo el valido fue tratado en el género de la dramaturgia llamada Comedia de la Privanza, ateniéndose a la comedia ¿Cómo ha de ser el privado?, de Francisco de Quevedo, por el relieve que presenta acerca del fenómeno del valimiento, así como de la controvertida relación de Quevedo con el régimen del Duque de Olivares, valido de Felipe IV.

Palabras clave: España del siglo XVII. ¿Cómo ha de ser el privado? Valido.

A personagem do valido, também conhecido como favorito ou privado, foi alvo de um debate político polêmico nos séculos XVI e XVII, especialmente no âmbito da Monarquia Hispânica, durante os reinados de Felipe III (1598-1621) e Felipe IV (1621-1665). Diversos autores se debruçaram sobre o tema para criticar a figura do favorito, enquanto outros defenderam a sua legitimidade como devotados amigos do rei, que o ajudavam na condução dos negócios da Monarquia. Podese entender essa polêmica a partir da proximidade entre monarcas e validos, cuja relação de amizade se insere no contexto da cultura política do Antigo Regime, em que não havia a separação entre as vidas pública e privada e, por conseguinte, entre as relações políticas e afetivas. Assim, considerado o melhor amigo do rei, o valido detinha a exclusividade do afeto régio, o que lhe permitia acesso ao coração das decisões políticas sobre o reino. Nessa perspectiva, a prática do valimento passava gradativamente do aconselhamento particular à direção política, o que gerava inveja no ambiente de competição da nobreza e um desequilíbrio de sua lógica interna (Oliveira, 2005; 2006; 2009; 2011; Dantas, 2006).

O debate em torno da função do valido como parte da engrenagem do governo não se restringiu aos teóricos da política e aos tratadistas. Entre os testemunhos da época, a literatura dramática, que conheceu grande fortuna ao longo do século XVII, teve na personagem do valido um tema de suma importância. ${ }^{1}$ Assim, constituiu-se um gênero de dramaturgia conhecido como Comedias de la Privanza. Este artigo, que parte dos resultados preliminares de investigação ainda em curso, pretende oferecer uma análise de como a figura dramática do valido foi imaginada e representada no âmbito dessa importante expressão

\footnotetext{
${ }^{1}$ Os autores que são representantes do teatro ibérico dessa época, como Francisco de Quevedo, Pedro Calderón de la Barca, Lope de Vega, Mira de Amescua, Tirso de Molina, dentre outros, estiveram às voltas com essa personagem.
} 
da cultura letrada do período, a qual se estabeleceu notadamente na Inglaterra e na Espanha devido ao fenômeno do favoritismo régio. Para tanto, toma-se por foco uma peça de Francisco de Quevedo (15801645), um dos mais renomados escritores espanhóis de todos os tempos. Embora não seja tão destacado por ter escrito comédias, Quevedo escreveu sua única comédia completa de atribuição segura, ¿Cómo ha de ser el Privado?, escrita provavelmente em 1629, que serve de paradigma para se pensar questões concernentes ao valido.

As Comedias de la Privanza tratam da complexa dinâmica do poder. Nesse tipo de peça a ascensão e a queda do favorito protagonista estão ligadas à ação das mudanças de fortuna, que em alguns momentos lhe permite gozar dos favores do monarca e em outros momentos lhe retira o seu estado de bonança. As comédias desse gênero têm como núcleo argumental as relações de poder e de fidelidade entre um soberano e seu privado (Peale, 2004, p. 126-128). Seus tópicos e temas literários recorrentes, como por exemplo, a inveja dos personagens antagônicos e as mudanças de fortuna, habitam o espaço cortesão. Dentro desse âmbito de domínio político, o aristocrata se sente obrigado a conseguir o favor da monarquia para consolidar ou melhorar seu status social, quer dizer, a sociedade cortesã luta por penetrar no círculo que rodeia o monarca. O rei ocupa uma posição central ou nuclear e seus favoritos são os distribuidores de seu patronato (Fernández, 2006, p. 248-249).

Segundo a especialista em literatura dramática espanhola dos séculos XVI e XVII, Teresa Ferrer Valls, os Dramas de la Privanza ${ }^{2}$ desenvolvem, sobre um fundo histórico, um tipo de conflito dramático que tem a ver com o processo de ascensão do protagonista no "pélago da corte" e as intrigas palacianas que desata. Além de abordarem o quanto a existência social depende da proximidade ao monarca, os Dramas de la Privanza refletem também a posição central que dentro do modelo de sociedade cortesã ocupam o monarca e seus favoritos. A corte aparece como um campo de forças em luta pelo poder, em que há um desequilíbrio da distribuição do patronato régio. Apesar de o monarca reconhecer os méritos do protagonista frente aos invejosos, os Dramas de la Privanza exprimem também o caráter humano dos reis

\footnotetext{
${ }_{2}$ Teresa Valls prefere a denominação Dramas de la Privanza, pois, para a autora, essa definição atende mais ao conflito dramático das peças e propõe a distinção genérica entre comédia e drama. Mas neste trabalho se prefere utilizar a expressão Comedias de la Privanza porque todas as obras teatrais profanas eram chamadas de "comédias", mesmo abrangendo os gêneros trágico e cômico. Além disso, com a obra Arte nuevo de hacer comedias en este tiempo, Lope de Vega cria o conceito de tragicomédia, defendendo a fusão do trágico com o cômico (Valls, 2004, p. 15-30).
} 
e sua capacidade de emitir juízos errados. Com isso, considerava-se a dupla pessoa do rei: divina enquanto instituição, humana enquanto homem. Abria-se, dessa forma, a possibilidade da crítica. Os Dramas de la Privanza também convidam às vezes à reflexão crítica sobre o espaço da corte em que se desenvolvia o jogo do poder, espaço em que se desdobra a inveja e a ambição, em que o monarca pode fazer e desfazer "homens", e está submetido à influência dos maus conselheiros e dos invejosos. Aliás, os discursos sobre a inveja ocupam um lugar destacado nos Dramas de la Privanza, pois colocam em risco a situação social do protagonista, sempre mediada por sua posição em relação ao monarca. Uma das constantes temáticas dos Dramas de la Privanza, portanto, é a posição do valido, apresentada como algo inerentemente transitório, submetido às mudanças de fortuna (Valls, 2004, p. 9-30).

No caso específico da corte inglesa ${ }^{3}$, Blair Worden oferece uma abordagem interessante acerca da preocupação do teatro com o poder dos favoritos reais da era moderna. Para o autor, examinar como o favoritismo aparece na cena teatral é observar a sensibilidade do drama no que tange às preocupações políticas da época, bem como sua capacidade de representá-las. A partir do final do século XVI até o começo do século XVIII, os grandes temas de representação dramática se concentraram na influência deletéria da personagem do valido sobre os monarcas, problemática que havia sido desenvolvida através de vários autores. ${ }^{4}$ Com efeito, o favorito é uma personagem teatral com características reconhecíveis que se estabelecem por um determinado vocabulário, o qual se desenvolve com hipérboles, distorções ou embustes a respeito dos feitos da vida política. Tendo em vista que o teatro trata da percepção pública do funcionamento do poder, os favoritos teatrais eram uma caricatura, percepção que sublinha a diferença entre a literatura e a vida. A ascensão dos favoritos é tratada como um capricho dos reis, que os promovem "cegamente", e suas carreiras produzem comentários sobre a efemeridade da fortuna. Em síntese, o problema dos favoritos é o problema do mau conselho, o monopólio do "ouvido" real: "Se urge a los monarcas a que confien en 'consejos'o 'consejeros', 'no en favoritos' y a que elijan a sus consejeros no 'por favor, sino por sus méritos'. Los favoritos dirigen 'facciones' que atrapan al principe para sus fines facciosos" (Worden, 1999, p. 229-237).

\footnotetext{
${ }^{3}$ Mesmo o teatro inglês não sendo objeto deste artigo, destaca-se paralelismos entre os autores ingleses e espanhóis que trataram a questão do valimento.

${ }^{4}$ Autores como Ben Jonson, John Marston, Samuel Daniel, George Chapman, John Day, Philip Massinger, John Fletcher, John Ford, James Shirley e sir William Davenant.
} 
A análise de Curtis Perry dos discursos sobre o favoritismo inglês no período entre meados da década 1580 até a eclosão da Guerra Civil mostra que o interesse na controvérsia referente aos favoritos teve importante papel no desenvolvimento da cultura manuscrita, a qual possibilitou o debate sobre matérias públicas além dos limites da corte. Figura chave da história da Inglaterra, o favorito se torna uma figura cujo papel provoca dúvidas sobre a interseção das esferas pessoal e pública em um sistema político tradicionalmente organizado em torno do patronato e da intimidade. Lançando mão de uma variedade de textos, incluindo poemas, libelos, sátiras, panfletos, Perry se utiliza especialmente de peças de teatro. $\mathrm{O}$ autor considera a emergente intervenção do teatro público como uma instituição, um desenvolvimento que emancipou a produção em massa de livres ficções políticas. De acordo com Perry, o discurso do favoritismo corrupto é o mais importante veículo "extraoficial" do período para explorar a questão sobre a natureza e os limites da monarquia pessoal dentro da constituição inglesa. Dentro dessa perspectiva que se deve entender o relacionamento erótico entre monarca e favorito, o que o autor chama de "favoritismo erótico", em que a sodomia, por exemplo, é sua figuração predominante. Os exemplos históricos demonstrativos da questão são a relação de Elizabeth I com o seu favorito Robert Dudley, conde de Leicester, difundida no polêmico libelo católico Leicester's Commonwealth, de 1584, bem como a relação homoerótica de Buckingham com James: Buckingham foi atacado por seus detratores como um sodomita. Com isso, o autor procura argumentar sobre uma profunda ambivalência sobre a legitimidade da intimidade pessoal como um mecanismo político e, assim, explorar questões referentes ao caráter da relação entre monarquia e sujeito a qual contribui para emergência das idéias proto-republicanas sobre o serviço público. Ou seja, os discursos sobre o favoritismo estão dentro dos debates históricos sobre a ascensão do pensamento republicano (Perry, 2006).

Sobre as Comedias de la Privanza se projetam muitos dos mecanismos de funcionamento de um modelo de sociedade cortesã - a corte francesa de Luis XIV - cujas peculiaridades foram estudadas por Norbert Elias. Esse modelo configura uma estrutura de poder que impõe algumas regras de jogo e alguns meios específicos de domínio, e em que a figura do monarca atua como chefe de família. Quer dizer, o Estado tem um caráter patrimonial, seu órgão central é a casa real (Elias, 2001, p. 66). Da proximidade ou da acessibilidade ao monarca dependia a existência social do nobre, sua identidade pessoal dentro de uma 
configuração social que marcava uma clara discriminação entre quem se movia na órbita do monarca e quem estava afastado de seu favor. Assim, Elias mostra a importância da etiqueta e dos rituais cerimoniais para a consolidação e para a manutenção da sociedade que vivia em torno do rei. Conforme o autor, "as alianças e rivalidades familiares, amizades e inimizades pessoais agiam como fatores normais no tratamento dos assuntos de governo, assim como em todos os assuntos oficiais" (Elias, 2001, p. 27). Para o rei, a etiqueta significava não só um instrumento de distanciamento, mas de dominação dos súditos, pois a figura do rei deveria se mostrar incomparável. Por isso, os ciúmes e as invejas que o rondavam eram sentimentos cultivados para manter o equilíbrio social (Elias, 2001, p. 133-158). Como assinala o autor:

Os cortesãos desenvolvem, no âmbito de determinada tradição, uma sensibilidade extraordinariamente refinada para as posturas, a fala e o comportamento que convêm ou não a um indivíduo segundo sua posição e seu valor na sociedade. Dedica-se uma atenção à sua casa, para verificar se está respeitando sua posição dentro dos limites tradicionais impostos pela hierarquia social. Essa atenção, assim como a consciência com que se observa tudo aquilo que um homem possui como referência ao seu valor social e ao seu prestígio, corresponde perfeitamente ao aparato de dominação absolutista da corte e à estrutura hierárquica de uma sociedade centralizada em torno do rei e da corte (Elias, 2001, p. 77).

Essa explicação nos coloca diante de como se devia proceder na sociedade de corte, o contrário desse comportamento podia gerar sérios problemas. Vejamos o exemplo de Mozart, que serviu ao arcebispo de Salzburgo, conde Colloredo, seu empregador e senhor. Para Norbert Elias, o comportamento de Mozart não se adequava aos modos da corte, pois tal personagem tinha o hábito de dizer o que sentia e pensava e não conseguia disfarçar seus sentimentos. Assim, Mozart abandonou o emprego em Salzburgo para tentar ganhar a vida como "artista autônomo", vendendo seu talento como músico e suas obras no mercado livre, enfim, produzindo pelo prazer da arte. Todavia a economia ainda era dominada pela aristocracia de corte, de forma que a produção artística era canalizada de acordo com o gosto da nobreza. As exigências da corte cerceavam a liberdade de criação do artista, este era tido como um artesão. Por isso, Mozart não conseguiu o sucesso que esperava do público vienense. Foi marginalizado, deixando o reconhecimento da singularidade de sua obra à posteridade. Morreu só, aos 35 anos, em 
1791. Em certo sentido, a figura do autor de Bodas de Fígaro estava à frente de sua época, representava o artista "livre" que confiava em sua inspiração individual e que não se achava inferior aos seus patronos, tornando-se uma expressão de protesto (Elias, 1994, p. 9-107).

Em contraposição, encontra-se a análise de Martin Warnke sobre como as cortes se relacionavam com os artistas e suas obras. Consoante o autor, ao artista da corte era atribuído um valor especial, visto que suas obras estavam entre os produtos intelectuais e não entre os artesanais. Sua tese questiona o conceito de que a autonomia da consciência do artista tenha surgido com as corporações na cultura burguesa das cidades do Renascimento e se desenvolvido, no século XIX, com o sujeito econômico-burguês. Segundo esse conceito, com o declínio da cidade, a liberdade de criação do artista estaria sujeita à corte dos soberanos absolutistas até após a Revolução Francesa, com a emergência da sociedade burguesa. Porém, para Warnke, as cortes foram responsáveis pelo desenvolvimento da autoconsciência dos artistas. A atribuição de postos e honrarias atraía os artistas da cidade para a corte, pois o trabalho nas cortes os libertava das obrigações impostas pelas corporações. $\mathrm{Na}$ corte, os artistas desempenhavam o "ofício da virtude", o que tornava possível sua ascensão à nobreza; já a hierarquia nas cidades mantinha os artistas na posição de artesãos, os quais eram considerados cidadãos, tendo que pagar impostos. Conforme o autor, a perspectiva aberta pelas cortes teria dado impulso aos frequentes esforços por emancipação dos artistas, os quais, após o declínio das cortes, foram expostos à crise, tornando-se, agora sim, marginais à sociedade, expostos ao mundo das trocas comerciais. Era, portanto, o final de um sistema de benefícios e funções que era a base do prestígio do trabalho artístico (Warnke, 2001, p. 15-20).

Norbert Elias e Martin Warnke oferecem um arcabouço histórico importante sobre a "atividade artística" nas cortes. Embora com posições epistemológicas diferentes, ambos contribuem para se compreender o universo em que o artista da corte estava inserido. Nesse sentido, interessa-se pelo ambiente em que se produziu uma figura como Quevedo. No entanto, enquanto Warnke trata da arte nas cortes européias do século XIII até a Revolução Francesa, Norbert Elias, quando trata do caso de Mozart, atém-se à segunda metade do século XVIII, momento em que já há um modelo burguês se organizando e um estatuto de artista se desenvolvendo. Já Francisco de Quevedo é um caso mais específico porque reflete um problema geral que é o do escritor preso à servidão do valido, momento em que não há efetivamente a iminência 
da emancipação do artista. Por outro lado, Warnke não nega que o artista da corte tinha de se adaptar às concepções estéticas de seus governantes, mas nem por isso a arte se restringiria a uma expressão de adulação ao poder, perdendo sua capacidade criativa, como passou a ser vista com a queda do Antigo Regime. Através dessa perspectiva, pode-se considerar as manobras de Quevedo em ¿Cómo ha de ser el privado?, aliando suas críticas veladas ao desejo de um ideal de valido.

Segundo J. Elliot, Olivares e Quevedo se acompanham mutuamente pela eternidade, pois cada um ajudou a construir e a destruir o outro. Quevedo foi desterrado em 1620 para a Torre de Juan Abad depois da queda de seu patrão, o duque de Osuna. Mas a morte de Felipe III (1621) e a queda de seu primeiro ministro, o duque de Uceda, transformaram o cenário político de Madrid, tempo em que surgiam novas oportunidades para Quevedo. Com o triunfo do conde-duque de Olivares e de sua facção, Quevedo começou a liquidar sua associação com Osuna e com os ministros de Felipe III e, em 1623, seu desterro chegou ao fim. Portanto, deve-se situar Quevedo no contexto do movimento de restauração e reforma dos últimos anos de Felipe III: para Quevedo e muitos outros castelhanos, os homens do novo regime pareciam oferecer a tarefa de erradicar os abusos que haviam proliferado no reinado anterior. Assim, no final da década de 1620 e início da década de 1630, Quevedo é situado no contexto da pequena camarilha de amigos e parentes de Olivares que havia posto seu talento à disposição de seu patrão. Entretanto, em 1634 e 1635, é possível detectar os primeiros sinais de distanciamento do regime de Olivares que converterá Quevedo em um opositor do condeduque. O que Quevedo desaprovava no governo de Olivares, sobretudo, era a exploração do rei por seus ministros e o seu isolamento do que sucede em seu reino. Por fim, a prisão de Quevedo em San Marcos de León, no ano de 1639, marcou a história literária e política da Espanha do século XVII (Elliot, 2007, p. 239-262).

Em ¿Cómo ha de ser el privado?, como o próprio título postula, Quevedo oferece uma definição de valido, apresentando um modelo ideal que, em resumo, é incorruptível. Se a maioria das Comedias de la privanza pretendem elucidar esse tema partindo de modelos históricos próximos, o enfoque é distinto em Quevedo, que defende a figura de um valido virtuoso, que carece de um antagonista explícito (Fernández, 2006, p. 255). A ação de ¿Cómo ha de ser el privado? se volta para a personagem moral da obra, o marquês de Valisero, identificado como o valido. O rei fica relegado a um segundo plano em detrimento do conselheiro, mas tal protagonismo pretende ser solucionado através de 
uma definição do valido como parapeito dos erros da Coroa (Fernández, 2006, p. 269-270): "No es outra cosa el privado que un sujeto, en quien la gente culpe cualquier accidente o suceso no acertado" (Quevedo y Villegas, 1988, p. 595). Por trás de cada personagem e lugar dessa comédia se reconhece um modelo: Nápoles representa Madrid; o rei Fernando é o rei Felipe IV, enquanto o marquês de Valisero é o condeduque de Olivares; a Infanta dona Margarita representa dona Maria, irmã do monarca espanhol. Esta quase contrai matrimônio com o Príncipe de Gales, que na comédia é o aspirante ao trono da Dinamarca. Seu rival na obra é o Príncipe da Transilvânia, que representa o rei da Hungria. O pai de Felipe IV, Felipe III, é referido como Don Juan. De resto, o duque de Sartabal encarna don Baltasar de Zúñiga, tio do conde-duque. A obra, dividida em três atos, sustenta-se sobre três ações dramáticas: a ação principal é a descrição do perfeito valido; e as duas outras ações secundárias são o matrimônio da Infanta e os devaneios amorosos do monarca (Fernández, 2006, p. 266-269).

Se Fernández Guerra considerava que a obra ¿Cómo ha de ser el privado? devia ter sido composta em 1628, Elliot a situa em 1629, retificando a proposição de Artigas, para quem a obra era de fins de 1627 ou começo de 1628. O critério de datação de Elliot remete a um fato histórico: o matrimônio da Infanta Maria com o rei da Hungria, motivo que aparece na comédia. Apesar de não aparecer no catálogo de Shergold y Varey de representações palatinas entre 1603 e 1699, a obra pode ter tido impacto teatral dentro do espaço cortesão. A comédia se incluiu dentro de uma lista de obras interpretadas em 1624, citada por Merimée. Desde a edição de Artigas (1927) se postulou que se representou nessa data e que foi anos mais tarde reelaborada (Fernández, 2006, p. 59-94).

Como ressalta Rafael Iglesias, a comédia não foi reconhecida à altura de outras obras de Quevedo até meados do século XIX. Graças ao esforço de Aureliano Fernández-Guerra, fez-se público o descobrimento do que parece ser o único manuscrito completo da obra, que só foi receber atenção e acessibilidade ao público quando don Miguel Artigas y Fernando publicou uma edição impressa em 1927. Mas tampouco em sua própria época a obra parece ter tido repercussão. Na introdução da mencionada edição de 1927, Miguel Artigas escrevia que considerava a comédia um trabalho medíocre, ainda mais se tratando de uma obra escrita por Francisco de Quevedo. Para Artigas, o único interesse que teria ¿Cómo ha de ser el privado? se devia às alusões aos fatos e personagens históricos (Iglesias, 2005, p. 267-268). Ele também estava 
de acordo com o que havia escrito Fernández-Guerra: "La comedia [...] es toda ella esencialmente política y encaminada a ponderar las esperanzas que engendraron en los españoles los primeros actos de Felipe IV' (Iglesias, 2005, p. 268).

Outros trabalhos apareceram seguindo a tradição de Artigas e Fernández-Guerra, tal como o de Manuel Urí, o qual afirma que a trama de ¿Cómo ha de ser el privado? "no representa más que un mero soporte argumental para ansalzar la figura del valido y mostrar cómo debía ser - cómo era, de hecho - el comportamiento del buen privado" (Iglesias, 2005, p. 268). Por sua vez, Elliott considera a obra como um trabalho descaradamente propagandístico. Pablo Jauralde, por outro lado, suspeita que, por detrás das bajulações ao rei e ao valido, podia haver certa forma de crítica devido à clara disparidade entre esses elogios e a realidade da Espanha do momento. De qualquer forma, ele também comenta que "es una obra de circunstancias, de las que prodigó nuestro escritor cuando tuvo necessidad de medrar en favores cortesanos" e que o propósito da comédia é "la justificación del valido, para lo que [Quevedo] no ahorra alabanzas" (Iglesias, 2005, p. 269). Portanto, a maioria dos estudiosos que examinaram ¿Cómo ha de ser el privado? estão de acordo ao considerá-la um mero instrumento de propaganda política a favor do conde-duque de Olivares e como uma forma vista por Quevedo para consolidar sua posição na corte. Nesse sentido, a peça está dentro do campo que podemos denominar como literatura propagandístico-laudatória (Iglesias, 2005, p. 270).

Nessa linha, encontram-se alguns trabalhos que analisaram o teatro do século XVII de uma forma geral como instrumento propagandístico do Estado. Tem-se, por exemplo, as obras do historiador espanhol José Antonio Maravall A Cultura do Barroco, de 1997, Teatro y Literatura en la sociedad barroca, de 1990, e Estudios de Historia del Pensamiento Español, de 1984; e o catedrático em literatura espanhola José María Díez Borque, em sua obra Sociologia de la comedia española del siglo XVII, de 1976.

Para Maravall, o teatro espanhol foi um dos meios de persuasão do Estado para atrair o público e enquadrá-lo na ordem social. Assim, a comédia oferecia modelos de comportamento para que o espectador se inserisse no sistema social. O teatro, segundo o autor, atingiu prodigalidade devido à necessidade de reforçar a propaganda, tendo em vista a situação de grave crise denunciada pelos escritores de problemas econômicos e políticos, incluindo militares. Por isso, para chamar a atenção do público e legitimar o poder do monarca, o teatro podia se 
servir de algumas inovações técnicas e temáticas, uma vez que a arte seria um dos setores que não causaria convulsões sociais (Maravall, 1997).

Nesse mesmo campo discursivo se destaca José María Díez Borque, em seu estudo das comédias a partir da análise da produção dramática de Lope de Vega, em que enfatiza a relação entre comédia e realidade no século XVII, no sentido da incorporação da realidade ao cenário. Conforme o autor, a comédia, como propaganda política, é acrítica, conseguindo canalizar o pensamento tradicionalista do homem no século XVII. A figura do valido se incorpora à comédia na medida em que os próprios dramaturgos aceitam a sua presença no centro do poder, tentando justificá-la. Assim, se lhe exige a lealdade ao rei, condição para sua existência, e visto que todos amam o rei, todos também devem aceitar quem ele ama. Afinal, a posição do rei na comédia é indiscutível, uma vez que ele é a condição da existência social (Borque, 1976).

No entanto, no estudo de Rafael Iglesias, ¿Cómo ha de ser el privado? é vista de uma perspectiva alternativa e complementar em relação às interpretações que têm sido comum. De acordo com o autor, ao lado do caráter propagandístico e apologético, deve-se levar em consideração o lado crítico e didático das comédias. À primeira vista ¿Cómo ha de ser el privado? parece um mero instrumento de propaganda política a favor do valido de Felipe IV, porém, observando mais atentamente, pode-se ver a existência de uma certa frustração por parte do autor com respeito ao governo de Olivares. A obra mostra elementos surpreendentes no contexto de uma comédia que havia sido encarregada originalmente pelo conde-duque de Olivares para defender sua política, sua pessoa e a imagem do rei, em um momento difícil do ponto de vista político. Um desses elementos que mais chama a atenção é a forma ambivalente que Quevedo se refere a certos antepassados de Felipe IV de Espanha. De forma indireta, ele nos recorda a prática de Felipe III, durante seu reinado, de ter deixado o governo nas mãos de seu privado, o corrupto duque de Lerma. Ao mesmo tempo, nessa parte se expressa implicitamente a esperança de Quevedo de que a quase completa usurpação das funções do rei por certos ministros não voltaria a acontecer (Iglesias, 2005, p. 270-272). A cena se encontra no primeiro ato, quando o suposto rei de Nápoles discute o "epíteto" que deseja colocar em uma estátua de seu pai:

Rey: Para el bronce que perfecto há de mostrar a mi padre a los siglos, que le cuadre, ¿qué alabanza, qué epiteto, qué renombre de famoso más propio se le pondrá? 
Marqués: Pienso que sabido está: de casto y de virtuoso.

Rey: Bien le están.

Marqués: A la oración se dió; con ella vencía y gobernaba.

Rey: Tenía celo de la religión.

Almirante: Igualó al gran rey don Juan en arrimarse a la ley y a lo justo.

Marqués: Fué gran rey el rey don Juan; mas le dan culpa todas sus historias.

Rey: ¿Cual?

Marqués: Haberse sujetado con extremo a su privado.

Almirante: Con todo, alcanzó mil glorias (Quevedo y Villegas, 1988, p. 595-596).

Não deixa de ser significativo que o suposto pai do rei de Nápoles tenha o mesmo nome de Juan II de Castela, que delegou funções a ministros como Don Álvaro de Luna, personagem central nas peças de Tirso de Molina. Apesar de tudo, independentemente das reservas que tinha sobre certos soberanos do passado, Quevedo respeitava e admirava a instituição da Monarquia, e acreditava na natureza sagrada da figura e da pessoa do rei (Iglesias, 2005, p. 271-273).

No começo do primeiro ato o rei don Fernando de Nápoles acaba de ser coroado. Inicialmente, o rei tenta encontrar com a ajuda de alguns de seus homens de confiança um renome que lhe projete para o futuro. No processo de busca de um renome, os personagens relembram as características definidoras de certos príncipes do passado, as quais deviam aspirar qualquer bom monarca: Felipe II o Prudente; Alfonso X o Sábio; Pedro I o Cruel; Alejandro Magno; e Felipe III, por detrás do apelido de "Santo" (modelo de piedade e ortodoxia religiosa). Através dos exemplos relativos à realeza, Quevedo não só tenta aconselhar o rei sobre os modelos do passado que devia seguir no transcurso de seu reinado, como também recomenda que características pessoais ou erros devia evitar. Ele queria que sua obra servisse como um guia moral e político para Felipe IV, ao estilo dos conhecidos espelhos de príncipes. As referências aos antepassados do rei não era somente uma forma de glorificação da Monarquia Hispânica, mas também uma forma de tentar abrir os olhos do soberano sobre as suas próprias limitações para que trate de corrigi-las. Os erros de reinados anteriores serviam de recordação de que Felipe IV não havia conseguido aplacar nenhum dos principais problemas existentes na Espanha desde há tempos. Assim, 
o rei, em sua coroação, se nomeará Justiceiro, fazendo uma defesa da justiça como virtude. O renome é importante porque se relaciona com as metas do rei para o reinado que começa (Iglesias, 2005, p. 275-277).

Em seguida, o rei deve escolher um valido. Este é descrito como um conselheiro, o qual alivia o peso dos tribunais. Sua escolha é feita de acordo com a virtude que cada proponente obteve quando foram validos. $\mathrm{O}$ almirante destaca a vigilância, o conde a fidelidade, enquanto o marquês de Valisero diz possuir a característica de desinteressado: "Virtudes son el cuidado y la verdad del prudente: pero yo fuera eminente en ser desinteresado" (Quevedo y Villegas, 1988, p. 594). Para compreender melhor essa parte, na qual vence o argumento do marquês, é importante lembrar que Olivares chegou ao poder se servindo de um programa de limpeza, o que tem relação com a queda de Lerma e as críticas que recebeu por buscar seu enriquecimento pessoal em detrimento do bem comum. Isso mostra a ambigüidade evidente entre por um lado o fomento dos interesses da Coroa e por outro dos interesses pessoais e de família. Assim, o valido ficou exposto a acusações de corrupção. A exigência de "limpeza de mãos" se converteu em uma das armas mais eficazes de oposição por parte dos que buscavam a derrubada do valido. Foi essa preocupação pela limpeza de mãos, por exemplo, que ajudou tanto Zúñiga quanto Olivares a deslocar os Sandoval e constituir um novo valimento. Destarte, Olivares teve que se apresentar ao mundo não como um privado ou valido, e sim como um ministro desinteressado, em conformidade com as normas neoestoicas em moda na sua geração (Elliot, 1997, p. 896). Outra questão a observar é que a relação entre o rei e o valido deveria ser desprovida de segundos interesses ou de objetivar ganhos pecuniários futuros, o que está ligado à chamada "economia dos afetos", que organizava a vida social no Antigo Regime. Segundo essa lógica, a entreajuda desinteressada, pelo menos no discurso, constituía-se em fundamento acerca de como se compreendia o mundo e as relações sociais (Oliveira, 2006, p. 123-130).

Ao mesmo tempo em que se sentiu honrado por ter sido escolhido como valido, o marquês reconhece os riscos de sua função. Ele comunica ao rei:

Aunque es, señor, honra mía que no llego a merecer, es linaje de castigo; que me das, con merced tal, todo el Reino por fiscal, y con fiscal, enemigo. Por un escudo me pones (sin que haya excepción) en quien rigurosos golpes den comunes mormuraciones. [...] Con invidia o con pasión le censuran de mil modos, y, aunque más le alaben todos, todos sus émulos son (Quevedo y Villegas, 1988, p. 595). 
Depois se reiteram o desinteresse e a filantropia de Valisero. Como expressa Violín, o gracioso da comédia, o privado terá que assumir culpas pouco gratas, transformando-se no bode expiatório que purgará todos os flancos problemáticos do país:

Si no hay pan, tiene el Valido la culpa (abrásele un rayo) porque no llovió por mayo, porque por mayo ha llovido. Si está sin tratos la tierra, el Privado lo ha causado, si hay paz es mandria el Privado, es un violento si hay guerra. En fin, si al vulgacho modo todas las cosas no van, habéis de ser un Adán, que tiene culpa de todo (Quevedo y Villegas, 1988, p. 597).

Segundo Teresa Valls, o "vulgacho", como proclama o gracioso na fala citada acima, pode ser considerado um antagonista tácito na obra de Quevedo. O "vulgacho" está sempre disposto a murmurar, e sua presença está voltada para o bem fazer político e pessoal do privado (Valls, 2004, p. 16).

Em segundo plano, ¿Cómo há de ser el privado? representa a trama da frustrada viagem do Príncipe de Gales a Madrid em 1623. Para que case com a Infanta Margarita, o marquês de Valisero exige a Carlos, Príncipe da Dinamarca, sua conversão para o catolicismo. Afinal, o soberano, como ministro de Deus na terra, deveria respeitar a ortodoxia religiosa acima de qualquer coisa e, se fosse necessário, castigar qualquer de seus súditos que ousassem descumprir suas ordens ou intentassem usurpar suas prerrogativas. No entanto, Carlos não aceita tal exigência, prometendo vingança. Desse modo, o sucesso da armada de Valisero estabelece relação com a jornada de Andaluzia que Felipe IV e seu séquito (incluindo Quevedo) empreenderam depois da partida do príncipe de Gales Carlos Estuardo ao romperem-se os tratos da boda com a Infanta. Nesse sentido, a obra mostra um sentimento contrário aos ingleses justamente no momento em que era prioritário para Olivares conseguir um tratado de paz com a Inglaterra (Iglesias, 2005, p. 293-294).

Em relação à vida sentimental do rei, a obra mostra um comportamento que não parece apropriado para uma pessoa de sua posição social e com suas responsabilidades. O rei nutre profundos sentimentos por uma dama da corte chamada Serafina e, quando está a sós com ela, parece um adolescente enamorado e chega a por em questão a sua integridade moral. Devemos levar em conta a merecida reputação de mulherengo que Felipe IV tinha na época, de modo que as cenas sentimentais da comédia podem ser entendidas como alusões indiretas 
às conhecidas promiscuidades do monarca espanhol. Além disso, quando este personagem encontra Serafina, não parece lembrar de que já era casado 5 . Curiosamente, a obra de Quevedo aparecera depois do momento em que fora tornado público o nascimento de um filho ilegítimo de Felipe $\mathrm{IV}^{6}$. No caso da comédia, Valisero ajuda o rei a resolver a sua situação com Serafina, dominando seus impulsos sexuais, porém, Olivares, na vida real, era acusado de fomentar a propensão do rei às mulheres e à festa (Iglesias, 2005, p. 285).

Os conselhos de Quevedo parecem uma crítica indireta à tendência de Felipe IV delegar funções ao conde-duque que correspondiam às obrigações do monarca. A pessoa que tivesse esse cargo deveria ser uma combinação entre conselheiro de confiança e secretário pessoal do rei. Cabia ao privado ter uma função apenas consultiva e em nenhum caso deveria usar a sua influência para fazer o rei tomar decisões contrárias a sua vontade (Iglesias, 2005, p. 280). Essa questão pode ser exemplificada nas seguintes palavras que o próprio Valisero dirige ao rei na obra, nas quais Quevedo parece aproveitar para recordar o monarca de seus deveres, expressando sua concepção de valido:

Sí, Señor, porque un Privado, que es un átomo pequeño junto al rey, no há de ser dueño de la luz que el sol le ha dado. Es un ministro de ley, es un brazo, un instrumento por donde pasa el aliento a la voluntad del rey. Si dos ángeles ha dado Dios al rey, su parecer más acertado ha de ser que el parecer del privado. Y así, se debe advertir que el ministro singular, aunque pueda aconsejar, no le toca decidir (Quevedo y Villegas, 1988, p. 596).

Em diversas partes da obra, Quevedo tenta mostrar ao rei e ao valido como se devia comportar um privado ideal e como atuava Olivares na realidade. Ao longo da peça, por exemplo, Valisero mostra sua determinação em não utilizar sua influência para ajudar aos que lhe pedem favores. Contudo, alguns cortesãos espanhóis sabiam que para ascender na corte precisavam primeiro do apoio de Olivares. As ações de Valisero podem ser interpretadas como uma defesa da idéia de que deveria ser o rei a fonte última de honras e de justiça no reino (Iglesias, 2005, p. 282-283).

\footnotetext{
${ }^{5}$ Lembre-se que a obra faz referência à rainha somente numa passagem do segundo ato.

${ }^{6}$ Em fins de 1620, Felipe IV manteve uma relação ilícita com a atriz apelidada "la Calderona", com quem teve um filho (Fernández, 2006, p. 272).
} 
Menos fiel à realidade ainda é o ocorrido durante uma audiência dada por Valisero na obra. Nela, um simples soldado reclama por não receber o que considerava uma justa recompensa por seus anos de serviço, mostrando-se insolente com o privado e com o rei (Quevedo y Villegas, 1988, p. 625). Segundo Iglesias, "La paciencia, modestia, humildad y absoluta falta de rencor que muestra Valisero en esta conversación parecian más propias de un santo que de uma persona de carne u hueso" (Iglesias, 2005, p. 284), ação que não havia de se esperar de Olivares, pois não era o tipo de pessoa que permitia a um subordinado questionar a equidade de suas ações. Quanto ao aspecto negativo compartilhado entre Olivares e Valisero está a referência à presença de sangue judeu, quando Valisero comenta que não é "linajudo" (Quevedo y Villegas, 1988, p. 626). Há críticas similares em outros trabalhos quevedianos, tais como El Critón de las tarabillas e Fiesta de toros literal y alegórica (Iglesias, 2005, p. 288-289).

No começo do segundo ato encontramos o Almirante comunicando ao valido a notícia da morte de seu filho em um acidente, a qual faz menção à morte da única filha de Olivares em 1627, a marquesa de Eliche. Apesar de ficar abalado, o personagem na obra segue com suas obrigações. Pouco tempo depois Valisero parece estar com extremo bom humor para achar graça das brincadeiras de Violín, que aparece para lhe pedir dinheiro disfarçado. A cena anterior possibilita ao espectador se sentimentalizar com a perda de Valisero, mas a linha argumental é carente de dramatismo e contraproducente do ponto de vista propagandístico. Supostamente, sua desgraça familiar não colocava em perigo que no futuro aparecessem parasitas capazes de saquear o tesouro do Estado, como havia acontecido com o clã dos Lerma (Iglesias, 2005, p. 288-289). Por outro lado, as catástrofes naturais não dependem da vontade do valido, e sim dos lances da fortuna. Assim, o destino nefasto não o faz suspender seus afazeres, mas reafirma a depuração de suas ambições. O valido perfeito devia conhecer seu fim para relativizar o papel que desempenha no grande teatro do mundo, lembrando que mais cedo ou mais tarde perderá sua fortuna (Fernández, 2006, p. 277).

Uma forma de crítica ao governo de Espanha aparece na cena em que Valisero se nega a assumir a responsabilidade pelos problemas de Nápoles na comédia. Quevedo apresenta o assunto da inflação descontrolada, a qual havia sido provocada principalmente pelas constantes mudanças no valor da moeda no governo de Olivares e de outros anteriores. Valisero responde ao Conde Castelomar sobre os 
rumores que corriam na cidade de que o privado era o culpado pelo aumento dos preços (Iglesias, 2005, p. 289-291):

[...] El pueblo tenga paciencia, porque a daños que han traído los tiempos no se ha podido dar remedio con violencia. Tiempo al tiempo se há de dar; y cuando de este accidente tuviera culpa el presente, yo, ¿qué puedo remediar? ¿Por ventura, mi tesoro es causa del común daño? ¿Recibo? ¿Vendo? ¿O engaño? También yo estos males lloro. Bien mi nombre me disculpa: Vali-Sero; vali tarde, dice mi título; aguarde el pueblo, sin darme culpa (Quevedo y Villegas, 1988, p. 608).

No último ato em particular, mencionam-se indiretamente vários elementos embaraçosos como a captura da frota da prata em 1628 por piratas holandeses, a ocupação da Bahia pelos holandeses, o frustrado ataque a Cádis em 1625 por parte de tropas anglo-holandesas, as dificuldades militares na Itália, a ruptura definitiva das negociações entre Inglaterra e Espanha em 1624, os problemas económicas da Coroa e da nobreza hispânica. Portanto, apesar dos elogios ao governo, é evidente a idéia de que a Espanha estava imersa em uma profunda crise (Iglesias, 2005, p. 292-293).

Tendo em vista a forma ambígua que Quevedo nos apresenta o conde-duque, não basta considerar a comédia apenas como uma forma de defesa de Olivares e de sua estratégia política. Quevedo tentou buscar uma forma de ajudar a solucionar ou atenuar os problemas do país, sem perder as vantagens e a proteção dos círculos mais altos do poder. Para isso, atendeu ao pedido de uma comédia feita por encomenda, louvando e defendendo o governo, informando alguns erros tomados pelo rei e seu valido e sugerindo pautas de comportamento e modelos a seguir. A tensão entre todas essas tendências contrapostas fez da obra um instrumento pobre tanto do ponto de vista político quanto dramático. É provável que a impossibilidade de reconciliar objetivos tão díspares impediu que a comédia fosse representada nos cenários de Madrid da Corte de Felipe IV. Como era de se esperar, a peça não fora em absoluto do agrado do conde-duque de Olivares. E parece ter sido escrita em um momento significativo na história das conflituosas relações entre Quevedo e Olivares. ¿Cómo ha de ser el privado? parece conter os primeiros indícios de um desacordo que, passados alguns anos, culminaria na ruptura definitiva entre o escritor madrileño e o conde-duque (Iglesias, 2005, p. 280-296). Mas mesmo que seu valor dramático seja questionável, ¿Cómo ha de ser el privado? é um 
documento historiográfico valioso e significativo no contexto político coevo. A comédia pode ser estudada como "documento", dado que ajuda a entender aspectos da vida política e social do século XVII. Além disso, a obra reflete algumas preocupações do autor, assim como o curioso papel que exerceu na corte de Felipe IV (Fernández, 2006, p. 243).

Em síntese, as Comedias de la Privanza se passam nas cortes dos reis, espaço de ação dos validos. Através de disputas inerentes ao universo da corte, o valido era alguém que conseguia ocupar a centralidade do afeto régio e das decisões políticas, causando um impacto na dinâmica interna das sociedades de corte. Poucos conseguiram galgar a posição de valido do rei, mas os que conseguiram, como Lerma, Olivares, Buckingham e Robert Dudley, marcaram o teatro da época ao se tornarem o topos central das comédias. Nesse sentido, através da investigação desse gênero de dramaturgia, pode-se discutir aspectos da configuração de poder do Antigo Regime, permitindo que se analise estratégias ascensionais e de luta no seio das cortes europeias, e, sobretudo, a projeção que isso tomou nas Comedias de la Privanza.

\section{Referências}

BORQUE, José María Díez. Sociologia de la Comedia Española del Siglo XVII. Madrid: Ediciones Cátedra, 1976. 369 p.

DANTAS, Vinícius Orlando de Carvalho. O conde de Castelo Melhor: um estadista na monarquia católica portuguesa (1662-1667). In: ENCONTRO REGIONAL DE HISTÓRIA, 12., 2006, Niterói. Usos do passado. Niterói: Anpuh, 2006. p. 1-5. Disponível em: <http://www.rj.anpuh.org/resources/rj/Anais/2006/ic/Vinicius\%20 de\%20Carvalho\%20Dantas.pdf>. Acesso em: 19 jun. 2012.

ELIAS, Norbert. A Sociedade de Corte: investigação sobre a sociologia da realeza e da aristocracia de corte. Tradução de Pedro Süssekin. Rio de Janeiro: Jorge Zahar Editor, 2001. 316 p.

ELIAS, Norbert. Mozart: Sociologia de um gênio. Tradução de Sergio Goes de Paula. Rio de Janeiro: Jorge Zahar Editor, 1994. 152 p.

ELLIOTT, John. España y su mundo (1500-1700). Madrid: Taurus, 2007. 370 p.

ELLIOTT, John. Unas Reflexiones acerca de la privanza española em el contexto europeo. Anuario de Historia del Derecho Español, Madrid: Boletín Oficial del Estado, v. 2, n. 67, p. 885-889, 1997. Disponível em: <http://www.uv.es/correa/privpub/elliot. pdf>. Acesso em: 01 maio 2013.

FERNÁNDEZ, María Hernández. El teatro de Quevedo. 2006. 751 p. Tese (Programa Historia e Invención de los Textos Literários Hispánicos) - Universidade de Barcelona, Barcelona, 2006.

IGLESIAS, Rafael. El imposible equilibrio entre el encomio cortesano y la reprimenda política: Hacia una nueva interpretación de ¿Cómo ha de ser el privado? de Quevedo. La Perinola. Revista de Investigación Quevediana, Navarra: GRISO - Universidad de 
Navarra, n. 9, p. 267-298, 2005. Disponível em: <http://bib.cervantesvirtual.com/servlet/ SirveObras/01350553122248188757680/029429.pdf\#search=\%22imposible $\% 20$ equilibrio\%20rafael\%20iglesias\%22\&page=27>. Acesso em: 15 out. 2008 .

MARAVALL, José Antonio. A cultura do Barroco: análise de uma estrutura histórica. Tradução: Silvana Garcia. São Paulo: Edusp, 1997. 418 p.

MARAVALL, José Antonio. Teatro y literatura en la sociedad barroca. Madrid: Crítica, 1990. 202 p.

MARAVALL, José Antonio. Estudios de historia del pensamiento español. Madrid: Ediciones Cultura Hispanica, 1984. Vol. III. 560 p.

OLIVEIRA, Ricardo de. Valimento, privança e favoritismo: aspectos da teoria e cultura política do Antigo Regime. Revista Brasileira de História, São Paulo: ANPUH Nacional, v. 25, n. 50, p. 217-238, 2005.

OLIVEIRA, Ricardo de. Amor, Amizade e Valimento na Linguagem Cortesã do Antigo Regime. Revista Tempo, Niterói: UFF - Departamento de História, v. 11, n. 21, p. 109132, 2006.

OLIVEIRA, Ricardo de. O melhor amigo do rei. A imagem da perfeita privanza na Monarquia Hispânica do século XVII. Revista História, São Paulo: História, v. 28, n. 1, p. 653-696, 2009.

OLIVEIRA, Ricardo de. Entre reis e rainhas: valimentos, favoritismos e disputas políticas na Europa do século XVII. Dimensões, Espírito Santo: Revista de História da Ufes, v. 26, n. 27, p. 216-238, 2011.

PEALE, C. George. Comienzos, enfoques y constitución de la comedia de privanza en la Tercera parte de las comedias de Lope de Vega y otros auctores. Hispanic Review, Pensilvania: University of Pensilvania, v. 1, n. 72, p. 125-156, 2004.

PERRY, Curtis. Literature and favoritism in early modern England. New York: Cambridge, 2006. 328 p.

QUEVEDO Y VILLEGAS, Don Francisco de. ¿Cómo ha de ser el privado? In: BUENDÍA, Felicidad (Org.). Obras completas de Don Francisco de Quevedo y Villegas. Obras em verso. 6. ed. Madrid: Aguilar, 1988. p. 592-635.

VALLS, Teresa Ferrer. El juego del poder: Lope de Vega y los dramas de la privanza. In: SEMINARIO INTERNACIONAL MODELOS DE VIDA EN LA ESPAÑA DEL SIGLO DEL ORO, 1., 2001, Madrid. Modelos de vida en la España del Siglo de Oro, El noble y el trabajador. Madrid: Casa Velázquez, 2004. p. 15-30.

WARNKE, Martin. O artista da Corte: os antecedentes dos artistas modernos. Tradução de Maria Clara Cescato. São Paulo: Editora da Universidade de São Paulo, 2001. 400 p.

WORDEN, Blair. Favoritos en la Escena Inglesa. In: ELLIOT, John; BROCKLISS, Laurence (Org.). El mundo de los validos. Madrid: Taurus, 1999. p. 229-264. 